\title{
600MW 超临界机组锅炉螺旋水冷壁质量控制
}

\section{Quality Control of 600MW Supercritical Unit Boiler Spiral Water Wall}

\author{
姜荣辉 \\ Ronghui Jiang
}

中国能源建设集才江苏省电力建设第三 工程有限公司

中国・江苏 镇江 212300

China Energy Engineering Grop Jiangsu No.3

Electric Power Construction Co.,Ltd.,

Zhenjiang, Jiangsu, 212300, China
【摘要】锅炉是火电厂中比较关键的设备, 而且对锅炉安装技术要求比较严格。论文重 点研究了火电厂锅炉安装工艺流程以及具体的关键安装技术和操作要求，同时提出了相 应的注意事项, 以供参考。

【Abstract】Boiler is the key equipment in thermal power plant, and the technical requirements for boiler installation are strict. This paper focuses on the boiler installation process and the specific key installation technology and operation requirements, and puts forward the corresponding precautions for reference.

【关键词】火电厂锅炉; 螺旋水冷壁; 组焊

【Keywords】thermal power plant boiler; spiral water wall; compound

【DOI】10.36012/peti.v1i2.834

\section{1 螺旋水冷壁的介绍及特点}

国电 $x \times$ 发电有限公司 $2 \times 600 \mathrm{MW}$ 锅炉是根据英国 MITSUI BABCOCK 公司技术设计、制造。炉膛水冷壁主要由 垂直管排和螺旋管组成, 上部水冷壁管排和下部螺旋管通过 中间集箱连接, 炉膛截面尺寸为: $22187.3 \mathrm{~mm} \times 15632.3 \mathrm{~mm}$ 。

螺旋管圈水冷壁主要由 436 根 $\phi 38 \mathrm{~mm} \times 6.5 \mathrm{~mm}$ (材质为 $15 \mathrm{CrMoG}$ )的管子围绕炉膛旋转组成, 中部螺旋管旋转角度为 $17.893^{\circ}$, 下部螺旋管旋转角度为 $17.821^{\circ}$ 和 $52.893^{\circ}$, 管子间距 为 $53 \mathrm{~mm}$ 。在水冷壁四周标高为 $46459 \mathrm{~mm}$ 处设置了螺旋管圈 出口集箱。在标高为 $46659 \mathrm{~mm}$ 处为螺旋管屏到垂直管屏的 转换点, 螺旋管屏到垂直管屏通过中部散管过渡 ${ }^{[1]}$ 。

\section{2 螺旋水冷壁安装方案选择}

由于螺旋水冷壁管子的不垂直性，管排在制作、运输中存 在扭曲、变形等因素, 导致管排安装时找正困难, 尺寸很难保 证。管排的间距比较小,鯺片宽度为 $15 \mathrm{~mm}$, 吊耳板只能选择板 厚 $\delta=10 \mathrm{~mm}$ 钢板, 因此, 必须制订科学合理的方案进行安装。

在地面组合成适当的尺寸和重量再进行吊装的优点是： 在地面组合尺寸容易控制,螺旋水冷壁的 $50 \%$ 焊口可在地面 焊接,鯺片密封的焊接工作量 $70 \%$ 在地面焊接。减少高空工 作量。

\section{3 解决螺旋水冷壁安装中主要困难点方法}

\section{1 螺旋水冷壁组合方式选择}

由于螺旋水冷壁为单片供货, 现场进行安装的焊口一周共 有 8 道焊口, 左右各 1 道, 前后各 3 道。在地面组合时, 决定将 前后水冷壁的中间焊口、左右侧水冷壁的焊口进行地面焊接。

\section{2 螺旋水冷壁吊装}

螺旋水冷壁吊耳板选用：插人螺旋水冷壁管排的钢板选 用 $\delta=10 \mathrm{~mm}$ 、宽度 $b=150 \mathrm{~mm}$ 的 $2235 \mathrm{~A}$ 钢板, 其余钢板选用 $\delta=$ $10 \mathrm{~mm}$ 的 Q235A 钢板。

3.2.1 吊耳板强度的计算及校核

以最重螺旋水冷壁管排组合件为例, 最重螺旋水冷壁管 排组合件重量为 $15.25 \mathrm{t}$, 按照 $16 \mathrm{t}$ 计算。每片管排上设置 4 只 吊耳, 每只吊耳受力为 $4 \mathrm{t}$ 。

吊耳孔所受剪切力:

$$
\begin{aligned}
\tau & =F / A=F /(2 \delta a)=40000 /(2 \times 16 \times 50) \\
& =25 \mathrm{MPa}<[\tau]=80 \mathrm{MPa}
\end{aligned}
$$

吊耳两侧拉应力:

$$
\begin{aligned}
\sigma & =F / A=F /(2 \delta b)=40000 /(2 \times 16 \times 50) \\
& =50 \mathrm{MPa}<[\sigma]=120 \mathrm{MPa}
\end{aligned}
$$

式中, $\delta$ 为吊耳板厚度; $a$ 为吊耳孔上方受剪最小高度 $; b$ 为吊 耳两侧受拉最小宽度。 
3.2 .2 插入管排的 $\delta=10 \mathrm{~mm}$ 钢板抗弯强度的计算及校核

由于每只吊耳:受力为 $4 \mathrm{t}$, 每块插入螺旋水冷壁管排的 $\delta=$ $10 \mathrm{~mm}$ 钢板受力为 $f=2 \mathrm{t}=2000 \mathrm{~kg}$ 。

螺旋水冷壁管子的直径为 $\phi 38 \mathrm{~mm}$, 考虑两侧吊耳板与管 排之间的间隙, $\delta=10 \mathrm{~mm}$ 钢板受力的有效长度为 $L=50 \mathrm{~mm}=$ $5 \mathrm{~cm} 。 \delta=10 \mathrm{~mm} 、 b=150 \mathrm{~mm}$ 钢板的抗弯模量 $W=2.5 \mathrm{~cm}^{3}, \mathrm{Q} 235 \mathrm{~A}$ 钢板的抗弯强度为 $\sigma_{\mathrm{s}}=155 \mathrm{MPa}$, 插人管排的 $\delta=10 \mathrm{~mm}$ 钢板抗 弯强度计算如下:

$$
\begin{aligned}
\sigma & =M / W=(f / 2)(L / 2) / W=(2000 / 2) \times(5 / 2) / 2.5 \\
& =1000 \mathrm{~kg} / \mathrm{cm}=100 \mathrm{MPa}<\sigma_{\mathrm{s}}
\end{aligned}
$$

所以,螺旋水冷壁吊耳能满足水冷壁组合件吊装的要求。

\section{3 地面组合控制设备的外形尺寸}

前后水冷壁组合的尺寸控制相对较简单，需拉好钢丝保 证两侧管屏管子管口在一直线上，保证吊装后焊口能与前后 侧的相焊接。把前侧的螺旋管屏按照图纸要求进行铺设、拼 装, 调整螺旋管排:管排长度的控制, 以螺旋角度、单片管屏管 子数量及管距计算出每一单片管屏垂直长度, 来定位管屏, 从 上向下管屏依次定位, 避免产生累计误差, 有管屏之间间隙不 适处通过增加或切割扁钢进行调整，使预组合的水冷壁的长 度、宽度和对角线符合图纸要求 ${ }^{[2]}$ 。

两侧进行组合时,由于两侧水冷壁为“[”和“]”状, 选择将 管子管口朝上进行组合, 由于转角为 $90^{\circ}$, 螺旋角度为 $17.893^{\circ}$, 且现场设备的弯曲角度有偏差, 无法对左右侧水冷 壁预组合进行控制, 左右侧水冷壁对角线偏差无法保证, 经讨 论采用利用距离安装焊口 2000mm（前后侧焊口距侧水冷壁 管排中心线距离 $880 \mathrm{~mm}$ ), 若设备焊口与前 (后)水冷壁第一 道焊口的长度为 $1 \mathrm{~mm}$, 则以设备焊口向前 (后)水冷壁第一道 焊口方向测量长度为 1 2000 $\mathrm{mm}$, 以该点为基准, 用钢丝拉好 直线, 以此为边, 并控制组合的对角线, 在预组合期间做好管 屏组合时的标志，以便管排吊装后组合时管排的组合、找正 ${ }^{[3]}$ 。

\section{4 管排运输安装}

管屏在运输时应在管屏上设置合理的起吊点, 采用钢丝 绳柔性吊装进行吊运, 每件组合后的管排上设置 8 个吊点, 起 吊利用 32t 门吊吊装, 并事先应制作一件 $17 \mathrm{~m}$ 长的运输架放 于 $25 \mathrm{t}$ 平板车上,防止管屏在运输过程中产生变形。

螺旋管屏安装先从右侧安装第一片组合件, 管排上端设 置 4 个起吊的吊点, 下端设置 4 个抬吊的吊点。用 $12.5 \mathrm{t}$ 卷扬 机卸车, $50 \mathrm{t}$ 炉顶吊配合 $5 \mathrm{t}$ 卷扬机进行抬吊, 从炉膛零米将管 屏扳直并吊装到垂直水冷壁的下端标高, 然后采用 4 只 $5 \mathrm{t}$ 链 条葫芦接钩、抛挂。

做好吊装管屏的初步找正定位工作，首先将螺旋水冷壁 上端的标高引到炉架上, 标高标志清晰。吊装前在垂直水冷壁 上设置 4 个吊点, 内外侧均挂有手拉葫芦以调整管屏的垂直
度和垂直管屏与螺旋管屏之间的距离, 安装吊挂装置后, 调整 好管屏与前炉室中心线, 从大板梁上挂钢丝, 以随时测量管屏 的垂直度和扭曲量 ${ }^{[4]}$ 。

管屏的吊装顺序为先吊装右前、左后侧的第一片管排, 形 成螺旋圈后安装与中间集箱连接的散管,然后按照先左右、后 前后的顺序进行。

对吊装的管排上端标高进行调整，保证螺旋水冷壁的管 排上端的水平，从而保证管子的螺旋角度和高空管排的垂直 度，将形成螺旋圈的管屏前后左右定位尺寸找正后并用型钢 进行加固, 经验收后进行与出口集箱的散管组合; 散管安装结 束后, 安装左右侧螺旋水冷壁。

安装左右侧的螺旋水冷壁，每安装组合的一片水冷壁及 时用型钢进行加固，保证管排的垂直及扭曲度。左右侧水冷壁 安装结束后, 将前后侧水冷壁管排向上靠安装管排 ${ }^{[5]}$ 。

\section{5 防止焊接变形的措施}

防止焊接变形的主要技术措施为交叉施焊、局部固定。螺 旋水冷壁鯺片密封焊缝累计长 $15000 \mathrm{~m}$, 层层叠叠, 所以控制 焊接变形是关键。首先应使鯺片与管子的镶嵌间隙尽量小, 对 填充的鯺片进行切割处理, 用砂轮逐片修磨, 以保证接触严 密, 防止焊后节距收缩。鯺片首先采用点焊, 焊缝长度和密度 要加大, 焊好 1 根管子鯺片后, 隔开 6 根再焊 ${ }^{[6]}$ 。同一鯺片规 定了焊接顺序, 采用内外交叉施焊的办法, 以防止局部焊接温 度过高, 产生变形。

\section{4 工程体会}

采用地面局部组合、全面预组合的方式,减少了设备安装 时的高空作业, 减少了脚手架搭设等辅助性工作, 提高了工程 安装的进度; 在施工中能步步进行质量控制, 减少了安装中的 累计安装误差, 提高了安装质量, 同时, 对焊接变形进行了优 化,使螺旋水冷壁的安装质量一直处于受控状态。

\section{参考文献}

[1]薛国华.探究火电厂锅炉安装工艺及关键技术措施 [J].科学技 术创新,2017(16):106.

[2]关凯,赵丽. 探究火电厂锅炉安装工艺及关键技术措施 [J].电子 世界,2017(20):201-202.

[3]程建杰. 火电厂锅炉安装工艺及关键技术措施 [J].科技创新导 报,2019,16(7):29-30.

[4]潘任伟.火电厂锅炉运行控制与故障预防 [J].民营科技,2013 (7):32 .

[5]宋永胜. 火电厂锅炉检修运行与维护技术分析 [J/OL].中国建 材科技 :1. [2019-11-19].http://kns.cnki.net/kcms/detail/11.2931.TU. 20180618.2007.054.html

[6]孙佳东. 火电厂锅炉低氮燃烧改造及运行优化[J].中外企业家, 2019(32):122. 